\title{
Economical and Reliable Expansion Alternative of Composite Power System under Restructuring
}

\author{
Ali S. Dalabeeh", Anwar ALMofleh², Abdallah R. Alzyoud ${ }^{3}$, Hindi T. Ayman ${ }^{4}$ \\ 1, 2, ${ }^{3}$ Electrical Engineering Department, Faculty of Engineering Technology, Al-Balqa' Applied University, Jordan \\ ${ }^{4}$ Najran University, College of Engineering, Najran University, Saudi Arabia
}

\begin{tabular}{l} 
Article Info \\
\hline Article history: \\
Received May 27, 2018 \\
Revised Jun 27, 2018 \\
Accepted Jul 24, 2018 \\
\hline
\end{tabular}

Keyword:

Adequacy

Composite

Expected

Interruption cost

Power systems

Reliability

\begin{abstract}
The paper intends to select the most economical and reliable expansion alternative of a composite power system to meet the expected future load growth. In order to reduce time computational quantity, a heuristic algorithm is adopted for composite power system reliability evaluation is proposed. The proposed algorithm is based on Monte-Carlo simulation method. The reliability indices are estimated for system base case and for the case of adding peaking generation units. The least cost reserve margin for the addition of five $20 \mathrm{MW}$ generating units sequentially is determined. Using the proposed algorithm an increment comparison approach used to illustrate the effect of the added units on the interruption and on the annual net gain costs. A flow chart introduced to explain the basic methodology to have an adequate assessment of a power system using Monte Carlo Simulation. The IEEE RTS (24-bus, 38-line) and The Jordanian Electrical Power System (46bus and 92-line) were examined to illustrate how to make decisions in power system planning and expansions.
\end{abstract}

Copyright $(0) 2018$ Institute of Advanced Engineering and Science. All rights reserved.

\section{Corresponding Author:}

Ali S. Dalabeeh,

Electrical Engineering Department, Faculty of Engineering Technology,

Al-Balqa' Applied University,

Amman 11134, Jordan.

Email: alidalabeeh@yahoo.com

\section{INTRODUCTION}

The traditional regulated power system has moved to a deregulated system. The price of the delivered energy and the quality of energy supply, including voltage quality and reliability of service are the main factors for composite power system under restructuring. [1]. Electric power systems have traditionally been organized and operated as vertically integrated utilities in which generation, transmission, and distribution facilities are managed by one company [2]. Social, economic, political and technical changes have forced the regulated industry to adapt. Competition has become the key factor driving the deregulation process in the electric power industry [3]. Generation and distribution services are provided by Independent generation and distribution companies, respectively, while electricity transmission systems with open access are overseen by the Independent System Operator (ISOs) or Regional Transmission Organizations (RTOs). The transmission system is most heavily used in the deregulated environment for the reason that large wholesale energy buyers are able to satisfy their needs by purchasing less expensive energy from geographically distant regions, which tends to overload the transmission system [2], [4], [5]. In the interest of all the market participants (generating companies, ISO, and customers) it is necessary to have system reliability information suitable to the new environment. As a consequence of restructuring of electric power systems, electric power utilities are facing increasing uncertainties regarding the economic and technical constraints. This has created increasing requirements for extensive justification of new facilities and increased emphasis on the justification of system costs and reliability. Composite system expansion planning 
is basically concerned with the addition of new generation and transmission facilities at a specified time in the future and at appropriate locations. The main concern of this work is to select the most economical and reliable expansion alternative in order to meet the new conditions, competition provides strong motivations for system planners to reevaluate the traditional deterministic approach used in composite reliability evaluation. Probabilistic reliability evaluation of composite generation and transmission systems provides the means to evaluate the benefits of providing system support [6]. The analytical approach is usually restricted to the evaluation of expected values and sometimes to a limited range of system parameters [4], [5]. When complex operating conditions are to be considered, it is advisable to go for Monte Carlo simulation techniques, which give the probability distributions of the reliability indices, in addition to the mean values. Planner tries to minimize investment and expected operating costs while supply reliability not exceed reestablished limits, for example in generation expansion planning Loss of Load Expectation (LOLE) should be less than one day in ten years [7]. However, it is not possible to ensure that the target reliability level reflects the economic impact of supply interruption and, hence, that the best balance between costs and reliability has been achieved [1]. Least cost planning approach tries to achieve the global minimization of investment costs, expected operation costs and supply interruption costs [2],[8].

Jordan electricity authority (JEA) established in 1967 in order to take over all generations and assess transmission activities in Jordan and sell power to two private distribution companies (JEPCO and IDECO) [9]. As a result of a process of restructuring and privatization, The National Electric Power Company (NEPCO) established in 1996 as the legal successor of JEA of electrical energy. In 1999 NEPCO was splitinto three companies [10], [11]: i) Central Electricity Generation Company (CEGCO), responsible for all generation, ii) Electricity Distribution Company (EDCO), responsible for distribution outside the concession areas of JEPCO and IDECO, iii) NEPCO was assigned the responsibility of management, operation and development of the high voltage transmission networks in addition to load dispatching and the operation of the interconnection with the neighboring countries (Egypt and Syria). In 2004 a new generation company called SPEGCO was established [11], [12]. The current model is applied based on the single buyer model where NEPCO buys from CEGCO, SPEGO and from neighboring countries through interconnection and sell it to the distribution companies bus respectively. (JEPCO, IDECO at EDCO). The buying process is based on annual contracts where the tariffs for the final costumer are set according the order of increasing consumption prespecified by the government.

Reference [13] proposed the concepts of relevant regions and regulative regions based on the concept of central relaxation to screen possible contingencies. References [1] described a methodology for calculating total system interruption costs in composite generation and transmission systems. The study in reference [14] was conducted in planning stages and for project implementation, whose goal is to define a network configuration which achieves minimum costs. Reference [15] presented a technique in which a generation company is represented by an equivalent multistate generation provider and the transmission system is represented by an equivalent multistate transmission provider using reliability network equivalent techniques. Reference [16] presented a time sequential Monte Carlo simulation technique in which general distribution system elements, operating models and radial configurations are considered. Reference [17], [18] evaluated the reliability assessment problem of low and the high DG penetration level of the active distribution system using the Monte Carlo simulation method. A Monte Carlo simulation technique in [13], was modified to include PV and wind energy sources. The focus of this paper is on the reliability evaluation of composite generation and transmission systems with special reference to frequency, duration related indices, and estimated power interruption costs at each load bus. When complex operating conditions are involved or the number of severe events is relatively large. Monte Carlo methods are often preferable [19]. The analytical approach is usually restricted to the evaluation of expected values and sometimes to a limited range of system parameters. Studies showed that power demand in Jordan is expected to continue its rapid increase over the coming 10 years. In this respect, proper steps need to be taken to prepare for the expected future increase in power demand. A step ahead before taking actions to increase power generation is to evaluate the adequacy of the existing power generation to meet the required demand. The deterministic techniques that are used by most power utilities in Jordan are not quite useful to precisely evaluate adequacy of the existing power generation. The commonly used probabilistic techniques (MCS simulation techniques) were applied on the Jordanian electrical system to precisely evaluate adequacy of the existing power generation. The aim of this work is to reduce the processing time with a negligible error, the system states with an associated state probability greater than a threshold value is considered while the remaining system states removed from the evaluation process, and to select the most economical and reliable expansion alternative of a composite power system to meet the expected future load growth Each considered system state is evaluated through an evaluation function. The evaluation function returns zero if it is a success state and a state probability if it is a failure state. The failure states that include outages up to a given order only considered also to reduce the processing time. 


\section{POWER SYSTEM RELIABILITY AND RELATED CONCEP}

Reliability is the measure of the overall ability of the power supply to meet the electrical energy needs of the customers [20], [21]. The word reliability in the context of power networks is the ability of the power system to provide an adequate supply of electric energy. System reliability can be made by considering the two basic and functional aspects of the system, adequacy and security. Systems adequacy relates to the existence of sufficient facilities within the system to satisfy the consumer load demand or system operational constraints. These include the facilities necessary to generate sufficient energy and the associated transmission load points. Adequacy is therefore associated with static conditions which do not include system disturbances. System security relates to the ability of the system to respond to disturbances arising within it.this paper is restricted to the adequte assessment of electric power systems. It is difficult, if not impossible, to evaluate the reliability of an entire power system [22], so traditionally, a power system is divided into three functional zones: generation, transmission, and distribution. Hierarchical levels can be created and defined in terms of the three functional zones [23].

The generation model and the load model represent the two main components of an electric power generating system that must be examined in order to evaluate the adequacy of the generating capacity. Both the generation and the load models are then combined to form the failure model [24], [25]. Both the generation and transmission facilities evaluation are usually referred as the evaluation of the reliability of the composite system or bulk power systems [18], [26]. At this level, adequacy evaluation becomes an assessment of the integrated ability of the generation and transmission systems to deliver energy to load points. The last level indicates an overall assessment that includes consideration of all three functional segments. A variety of criteria and techniques have been developed and utilized by numerous utilities over a number of decades [20]-[24], [27]-[28]. Of these, deterministic and probabilistic techniques are the ones widely used for the evaluation of generating capacity adequacy.

Deterministic techniques were used early on in practical applications, and some power system utilities are still dependent on these techniques. Their major disadvantage is their failure to take into account the stochastic nature of the system behavior that results from customer demands or component failures. In the past, a number of factors, such as lack of reliability data and computational resources, created a preference for the use of deterministic techniques. However, with the availability of the applicable reliability data and advancements in computational technologies, these factors no longer apply, and logic now dictates the use of probabilistic techniques that can include consideration of the stochastic nature of the behavior of power systems, which has such a critical influence on power system reliability [27]. The reliable performance of a particular configuration (alternative) can best be expressed by calculating appropriate indices. These indices can be calculated for each of the three hierarchical levels. These indices assist utility system planners and operators to compare alternate plans or operating procedures in specific segments of a power system.

\section{ADEQUACY ASSESSMENT OF COMPOSITE POWER SYSTEM}

An outage history of each unit can be generated by simulating its failure and repair with respect to time using (1) and (2), respectively, where MTTF and MTTR are the mean times to failure and repair, respectively, of the unit

$$
\begin{aligned}
& \text { Up Time }=- \text { MTTF } \times \operatorname{Ln}\left(\mathrm{x}_{1}\right) \\
& \text { Down Time }=- \text { MTTR } \times \operatorname{Ln}\left(\mathrm{x}_{2}\right)
\end{aligned}
$$

The power available from all the generating units is combined to create the generation model, which is compared with the hourly load and the accepted deterministic criterion to identify the success and the failure states. The simulation proceeds chronologically from one hour to the next for repeated yearly samples until specified convergence criteria are satisfied. The number of success states $n(H), n(R)$ failure states, and their duration's $t(H)$ and t $(\mathrm{R})$ are recorded for the entire simulation. The system success and failure indices are evaluated using (3) $-\mathrm{v}(5)$, where $\mathrm{N}$ is the total number of simulated years:

$$
\begin{aligned}
\mathrm{P}(\mathrm{H}) & =\frac{\sum_{\mathrm{i}=1}^{\mathrm{n}(\mathrm{H})} \mathrm{t}(\mathrm{H})_{\mathrm{i}}}{\mathrm{N} \times \text { Year in hrs }} \\
\text { LOHE } & =[1-\mathrm{P}(\mathrm{H})] \times \text { Yearsin hrs } \\
\text { LOLE } & =\frac{\sum_{\mathrm{i}=1}^{\mathrm{n}(\mathrm{R})} \mathrm{t}(\mathrm{R})_{\mathrm{i}}}{\mathrm{N}}
\end{aligned}
$$


The two state models considered in the study are presented as

$$
\begin{aligned}
& \text { FOR }=U=\frac{\sum \mathrm{T}_{\text {down }}}{\sum \mathrm{T}_{\mathrm{up}}+\sum \mathrm{T}_{\text {down }}} \\
& \text { FOR }=\mathrm{U}=\frac{\lambda}{\lambda+\mu}
\end{aligned}
$$

The flow chart shown in Figure. 1 illustrates the procedures and sequence which were carried out in order to achieve the adequacy assessment using analytical techniques.

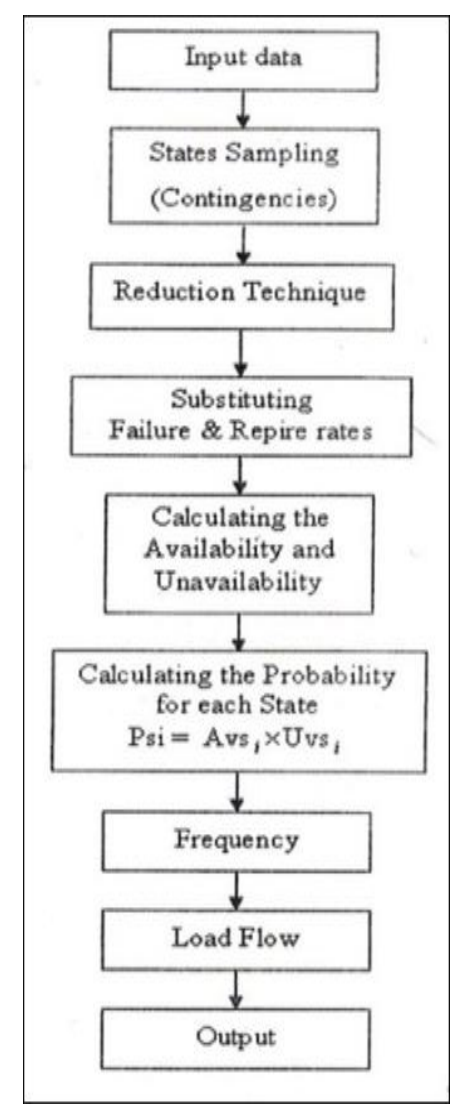

Figure 1. Flow chart of adequacy assessment using analytical techniques

The Monte Carlo method is based on sampling the probability distribution of the component state duration. In this approach, chronological component state transition processes for all components are first simulated by sampling. The chronological system state transition process is then created by a combination of chronological component state transition process [6]. The flow chart shown in Figure 2 explains the basic methodology to have an adequacy assess for a power system using Monte Carlo Simulation. 


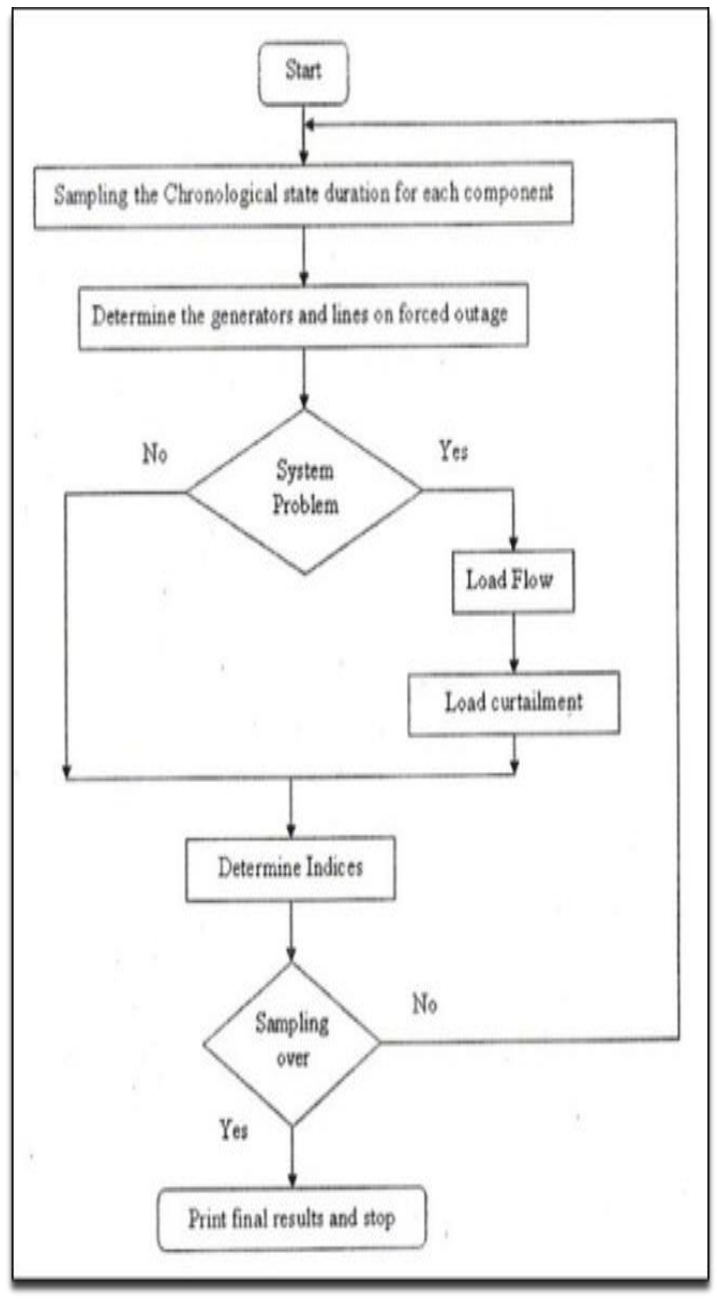

Figure 2. Flow chart for adequacy assessment using monte carlo simulation

\section{ADEQUECY INDICES}

Power system reliability is usually reflected by indices $[11,19,22,29]$ that measure the reliability and adequacy of the system. The indices most widely accepted and used for the assessment of generating capacity adequacy are:

a) LOLE denotes the expected average number of hours/days in a designated period during which the existing generating capacity fails to meet the demand.

b) LOEE indicates the expected amount of energy not supplied due to a shortage of generation capacity.

c) LOLF is the loss of load frequency.

d) EENS is the expected energy not supplied.

e) EIC is the Expected Interruption Cost

f) IEAR is the Interrupted Energy Assessment Rate

\section{RESULTS}

Using Monte Carlo Method IEEE RTS (24-bus, 38-line) and The Jordanian Electrical Power System (46-bus and 92-line) were examined to illustrate how to make decisions in power system planning and expansions.

\subsection{Reliability Assessment in Generation Planning is illustrated using the IEEE RTS}

The IEEE RTS consists of 24 bus locations connected by 38 lines and transformers [8], the annual peak load of $2850 \mathrm{MW}$, and the total installed generating capacity is $3405 \mathrm{MW}$. The generating unit state 
durations are assumed to be exponential, no de-rated states are considered, and units were assumed to have the same failure data of the 20MW units with capital cost of $17 \mathrm{M} \$$ per unit.

\subsubsection{Base Case}

In this case, the generating unit state durations are assumed to be exponential and no directed states are considered. The estimated reliability indices are shown in Figure 3. These results are for 2500 sampling years.

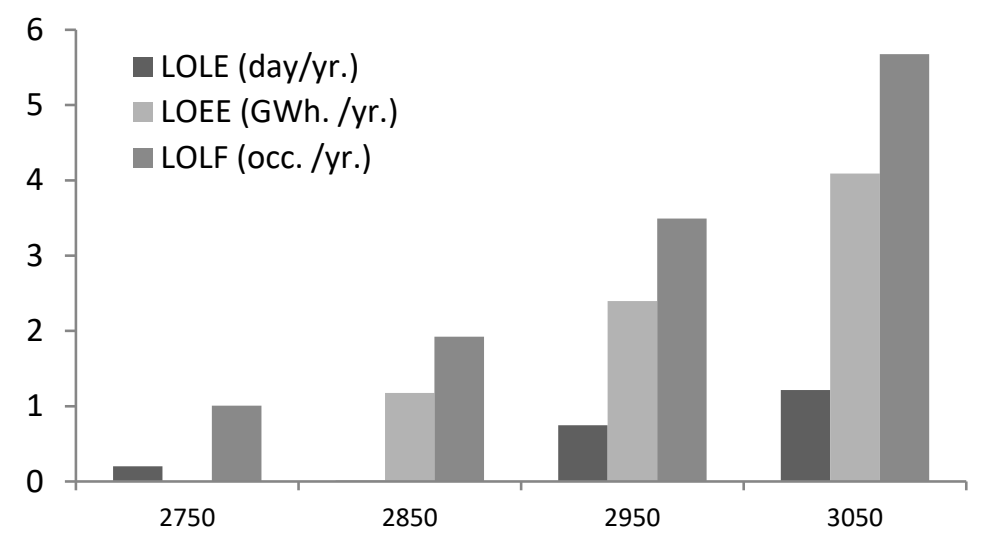

Figure 3. The estimated reliability indices in generation planning using the IEEE RTS at the base case

\subsubsection{Peaking Units Case}

This case is the same as the base case for the annual peak load of $2850 \mathrm{MW}$, except that additional 25MW gas turbine units are installed as peaking units. The data for the peaking units are given in Table 1.

Table 1. The data for the peaking units

\begin{tabular}{cccc}
\hline Capacity(MW) & $\begin{array}{c}\text { Mean Time to } \\
\text { failure(hr) }\end{array}$ & $\begin{array}{c}\text { Average Repair } \\
\text { Time }(\mathrm{hr})\end{array}$ & $\begin{array}{c}\text { Start failure } \\
\text { probability }\end{array}$ \\
\hline 25 & 550 & 75 & 0.01 \\
\hline
\end{tabular}

The simulation results for 2500 sample years are shown in Figure 4, shows that the addition of peaking units improves the generating system adequacy.

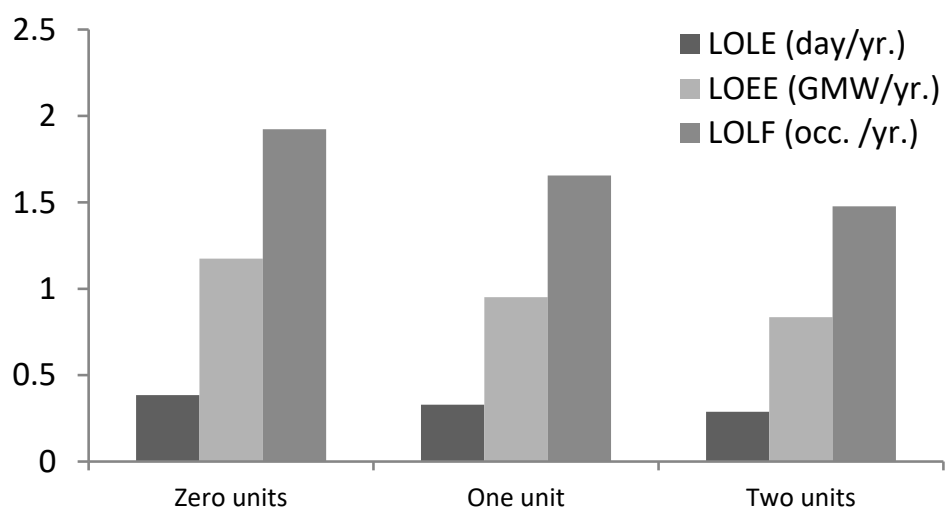

Figure 4. The estimated reliability indices in generation planning using the IEEE RTS at peaking units case 


\subsubsection{Reliability worth Assessment in Generation Planning for IEEE RTS}

The initial analysis was done by assuming that the total system peak load is increased from $2850 \mathrm{MW}$ to $3000 \mathrm{MW}$ while the annual load curve shape remains unchanged. The total installed capacity provided by 32 generating units is 3405MW.The associated reserve margin is $13.5 \%$ of this system peak load. The purpose of the study is to determine the least cost reserve margin for the addition of five 20MW generating units sequentially. These units were assumed to have the same failure data of the 20MW units with capital cost of $17 \mathrm{M} \$$ per unit. The annual investment cost was calculated using the present value method under the assumption of a $30 \mathrm{yr}$ economic life and a $10 \%$ discount rate. The annual investment cost is $1802 \mathrm{~K} \$ / \mathrm{yr}$. Table 2 presents the expected interruption, investment, and operating cost in $\mathrm{K} \$ / \mathrm{yr}$, for the base case and with sequential addition of 20MW units.

Table 2. The interruption, investment, and operating cost with adding 20MW units

\begin{tabular}{ccccc}
\hline Added units & Reserve Margin\% & EIC $(\mathrm{k} \$$ /year $)$ & Investment Cost $(\mathrm{k} \$$ /year $)$ & Operating cost(k\$/year) \\
\hline 0 & 13.5 & 16665.30 & 0 & 126740 \\
1 & 14.16 & 14313.00 & 1802 & 126930 \\
2 & 14.83 & 12635.01 & 3606 & 127010 \\
3 & 15.50 & 11403.77 & 5406 & 127060 \\
4 & 16.17 & 10329.32 & 7208 & 127090 \\
5 & 16.83 & 8969.76 & 9010 & 127120 \\
\hline
\end{tabular}

It can be seen that the Expected Interruption Cost (EIC) decreases rapidly as additional capacity is added to the system while the operating costs increase slowly. An increment comparison approach can be used to illustrate the effect of the added units to the interruption and operating costs in $\mathrm{K} \$ / \mathrm{yr}$ for the whole system, as shown in Table 3. It can be seen that the maximum benefit or the least cost reserve occurs with the addition of one 20MW unit.

Table 3. Increment cost and annual net gains with the additional 20MW units

\begin{tabular}{ccccc}
\hline Added Units & EIC (1) & Investment Cost (2) & Operation Cost (3) & Annual net gain $(1)-[(2)+(3)]$ \\
\hline 0 & 0 & 0 & 0 & 0 \\
1 & 2352.3 & 1802 & 190 & 360.3 \\
2 & 4030.29 & 3604 & 270 & 156.29 \\
3 & 5261.53 & 5406 & 320 & -464.47 \\
4 & 6335.98 & 7208 & 350 & -1222.02 \\
5 & 7695.54 & 9010 & 380 & -1694.46 \\
\hline
\end{tabular}

\subsection{Reliability worth Assessment in composite system planning is illustrated using JEPS}

The basic annual peak load for the test system is $2230 \mathrm{MW}$ and the total installed generating capacity is $2525 \mathrm{MW}$. The basic data for the JEPS [9] is used to evaluate the annual expected interruption costs of four alternatives:

A1: The addition of a $132 \mathrm{KV}$ double circuit OHL between Buses 17 and 19 (70KM).

A2: The addition of a 400KV double circuit OHL between Buses 1 and 4 (360KM).

A3: The addition of a generating unit at Bus 20 (20MW).

A4: The addition of a generating unit at Bus 4 (20MW).

The annual investment cost was calculated using the present value method under the assumption of a $30 \mathrm{yr}$ economic life and a $10 \%$ discount rate. Four Alternatives for load increment $0.0 \%, 2 \%, 4 \%, 6 \%, 8 \%$, and $10 \%$. Figure 5 shows the annual expected EENS, EIC, and IEAR in the JEPS at Different Load increment Levels $(0.0 \%-10 \%) \mathrm{MW}$. 


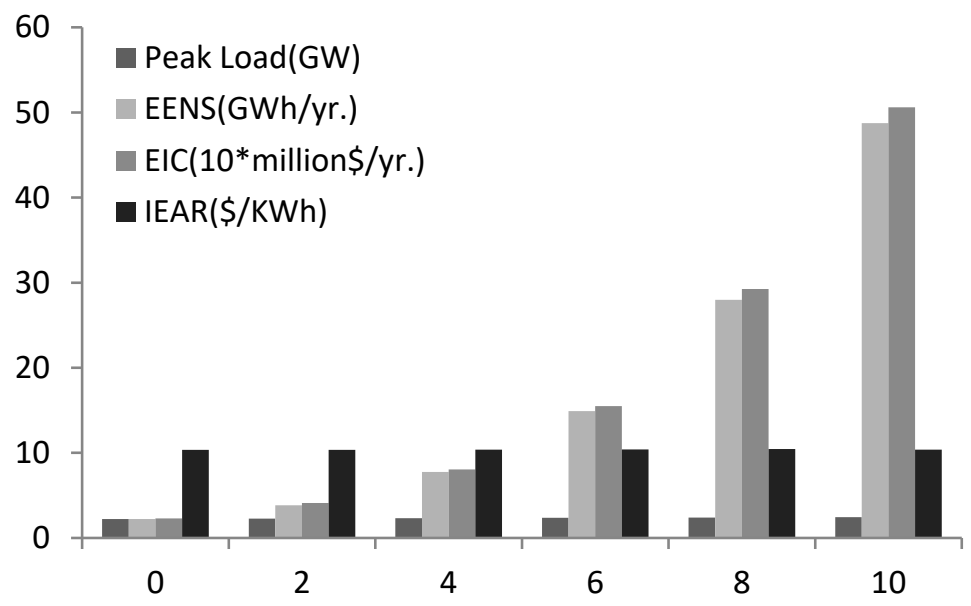

Figure 5. System EENS, EIC, and IEAR in the JEPS at different load levels

The annual expected interruption costs (EIC) of the base system and the four Alternatives for load increment $0.0 \%, 2 \%, 4 \%, 6 \%, 8 \%$, and $10 \%$ are shown in Table 4 .

Table 4. EIC Indices of the Base System and Four Alternatives for JEPS(K\$/yr.)

\begin{tabular}{cccccc}
\hline \multirow{2}{*}{ Load Increment \% } & \multirow{2}{*}{ Base System } & A1 & A2 & A3 & A4 \\
\hline O.O & 22982.39 & 20859.02 & 21907.5 & 16862.99 & 8329.92 \\
2.0 & 41225.69 & 38582.92 & 39282.92 & 33804.63 & 19563.11 \\
4.0 & 80572.70 & 77717.7 & 78117.7 & 62705.06 & 41502.38 \\
6.0 & 154918.22 & 151813.3 & 153857.9 & 118620.4 & 79556.49 \\
8.0 & 292524.49 & 286715.72 & 289051.6 & 239444.4 & 145612 \\
10.0 & 506006.02 & 499881.64 & 502524.7 & 418796.1 & 294731.1 \\
\hline
\end{tabular}

It can be seen that Alternative A1 is the addition of a $132 \mathrm{KV}$ double circuit OHL between Buses 17 and 19 which leads to much lower EIC than A2. This indicates that the different line addition location has completely different impacts on composite system reliability.A2 has basically the same EIC indices as the base case. This means that the addition of a 400KV double circuit OHL between Buses 1 and 4 does not improve the reliability of the system. Further analysis can be conducted to evaluate the total cost, which is the sum of annual expected interruption costs and annual investment for the alternatives. The economic life of the power system facilities was assumed to be 30 years and the discount rate $10 \%$. The unit capital cost and the annual investment for all alternatives can be shown in Table 5.

Table 5. The Unit Capital Cost and the Annual Investment for all Alternatives

\begin{tabular}{cccc}
\hline NO. & Alternative Description & Unit capital cost & Annual Investment \\
\hline A1 & Add line 132KV(70KM)@ Bus 17 -19 & $135 \mathrm{~K} \$ / \mathrm{KM}$ & 1002.40 \\
A2 & Add line 400KV(360KM)@ Bus 1 - 4 & $400 \mathrm{~K} \$ \mathrm{KM}$ & Rejected \\
A3 & Add GT gen(20MW)@ Bus 20 & $17 \mathrm{M} \$$ & $1803.33 \mathrm{~K} \$ / \mathrm{yr}$. \\
A4 & Add ST get(120MW)@ Bus 4 & $120 \mathrm{M} \$$ & $12730.00 \mathrm{~K} \$ / \mathrm{yr}$. \\
\hline
\end{tabular}

For example, at the present load level ( $0.0 \%$ increment), Alternative A1 can reduce the expected interruption cost by $2123.37 \mathrm{~K} \$ / \mathrm{yr}$.(2298239-20859.02). This reduction in much larger than its annual investment of $1002.4 \mathrm{~K} \$ / \mathrm{yr}$, and therefore Alternative A1 is a beneficial option. Table. 6 shows the alternatives annual net gain. This indicates that the addition of the $20 \mathrm{MW}$ unit is the best option even when the load has $10 \%$ growth. 
Table 6. Alternatives Annual net gain at Different Load Levels

\begin{tabular}{cccccc}
\hline \multirow{2}{*}{ Load Increment \% } & \multirow{2}{*}{ Base System } & A1 & Alternative Annual net gain (K\$/yr.) & A4 \\
\hline 0 & 22982.39 & 1120.97 & -14203.51 & 4316.06 & 1922.47 \\
2 & 39847.65 & 1640.37 & -13335.63 & 5617.73 & 8932.58 \\
4 & 80572.69 & 1852.59 & -12823.41 & 16064.30 & 26340.31 \\
6 & 154918.22 & 2102.52 & -14218.12 & 34494.45 & 62631.73 \\
8 & 292524.49 & 3613.04 & -12998.77 & 50083.47 & 132989.21 \\
10 & 506006.02 & 5121.98 & -11797.12 & 85406.55 & 198544.89 \\
\hline
\end{tabular}

\section{CONCLUSION}

In the interest of all the market participants (generating companies, ISO, and customers) it is necessary to have system reliability information suitable to the new environment. When complex operating conditions are to be considered, it is advisable to go for Monte Carlo simulation techniques, which give the probability distributions of the reliability indices, in addition to the mean values. As a consequence of restructuring of electric power systems, electric power utilities are facing increasing uncertainties regarding the economic constraints. This has created increasing requirements for extensive justification of new facilities and increased emphasis on the justification of system costs and reliability. Composite system expansion planning is basically concerned with the addition of new generation and transmission facilities at a specified time in the future and at appropriate locations. The objective is to select the most economical and reliable expansion alternative in order to meet the expected future load growth. For a restructured composite power system to enhance the reliability indices and minimize the interruptions cost of a long term expansion evaluating the reliability indices in long term planning and specifying the best feasible expansion alternative from multi proposed alternatives should be done.

\section{REFERENCES}

[1] J. C. C. O. Mello, et al., "Evaluation of reliability worth in composite system based on pseudo-sequential monte carlo simulation," IEEE Transactions on power System, vol/issue: 9(3), 1994.

[2] C. Barbulescu, et al., "Transmission Planning - a Probabilistic Load Flow Perspective," International Journal of Electrical Power and Energy System Engineering, vol/issue: 2(1), 2009.

[3] D. Chattopadhyay and J. Momoh, "A Multi-objective Operations planning Model with Unit Commitment and Transmission Constraints, Power Systems," IEEE Transactions, vol/issue: 14(3), pp. 1078-1084, 1999.

[4] R. Billinton and R. Allan, "Reliability Evaluation of Power Systems," Plenum Press, New York, NY, 1996.

[5] R. Billinton and R. Allan, "Reliability evaluation of engineering systems Concepts and techniques," Plenum Press, New York, NY, 1992.

[6] J. Endrenyi, "Reliability Modeling in Electric Power System,” John Wiley, 1978.

[7] A. Bhuiya, "A Sudy of Bilateral Contracts in a Deregulated Power System Network," University of Saskatchewan, National Library of Canada, 2004.

[8] R. Billinton and W. Li, "Reliability Assessment of Electric Power System Using Monte Carlo Methods," Plenum Press, New York, NY, 1994.

[9] National Electrical Power Company (NEPCO), "Electricity in Jordan, Development of Electricity," Retrieved from: http://www.nepco.com.jo/english_improve.html

[10] Central Electricity Generating Company, Annual Report, Amman- Jordan, 2016.

[11] D. M. Dalabeih, et al., "Reliability Assessment of a Restructured Power System."

[12] A. K. Dalabeeh, et al., "Reliability Worth Assessment in Composite Power System Planning and Operation," Modern Applied Science, vol/issue: 8(5), 2014.

[13] G. Yongji, et al., "Composile System Reliability Evaluation based on Monte-Carlo Simulation Combined with Outages Screening," IEEE transactions on Power Systems, vol/issue: 14(2), 1999.

[14] O. Bertoldi, et al., "Monte Carlo Approach in Planning Studies: an Application to IEEE RTS," IEEE Transactions on Power Systems, vol/issue: 3(3), 1988.

[15] P. Wang and R. Billinton, "Reliability assessment of a restructured power system using reliability network equivalent techniques," IEE Proc.-Gener. Transm. Distrib., vol/issue: 150(5), 2003.

[16] R. Billinton, et al., "Teaching Distribution System Reliability Evaluation Using Monte Carlo Simulation," IEEE Transactions on Power Systems, vol/issue: 14(2), 1999.

[17] Shaoyun G., et al., "Reliability Assessment of Active Distribution System Using Monte Carlo Simulation Method," Journal of Applied Mathematics, 2014.

[18] R. Billinton and A. Sankarakrishnan, "A comparison of monte carlo simulation techniques for composite power system reliability assessment," Proc. WESCANEX 95, IEEE Communications, Power and Computing Conference, Winnipeg, Canada, vol. 1, pp. 145-150, 1995.

[19] A. C. G. Melo, et al., "A Conditional Probability Approach to the Calculation of Frequency and Duration Indices in Composite Reliability Evaluation," IEEE Trans. On Power Systems, vol/issue: 8(3), pp. 1118-1125, 1993. 
[20] R. Billinton and R. N. Allan, "Power-system reliability in perspective," Electron. Power, vol/issue: 30(3), pp. 231236, 1984.

[21] W. Lia and J. Zhoub, "Probabilistic reliability assessment of power system operations," Elect. Power Compon. Syst., vol/issue: 36(10), pp. 1102-1114, 2008.

[22] A. Almutairi, et al., "Evaluation of the Generating Capacity Adequacy of the Saudi Arabian Central Operating Area," Electric Power Components and Systems, vol/issue: 42(1), pp. 83-90, 2014.

[23] R. Allan and R. Billinton, "Probabilistic assessment of power systems," Proc. IEEE, vol/issue: 88(2), pp. 140-162, 2000.

[24] R. Billinton and L. Gan, "Use of Monte Carlo simulation in teaching generating capacity adequacy assessment," IEEE Trans. Power Syst., vol/issue: 6(4), pp. 1571-1577, 1991.

[25] R. Billinton and D. Huang, "Basic concepts in generating capacity adequacy evaluation," 9th International Conference on Probabilistic Methods Applied to Power Systems, Sweden, pp. 1-6, 2006.

[26] M. A. H. El-Sayed and H. J. Hinz, "Composite reliability evaluation of interconnected power systems," Elect. Power Compon. Syst., vol/issue: 24(6), pp. 609-622, 1996

[27] R. A. Billinton and R. N. Allan, "Generating capacity-basic probability methods," Reliability Evaluation of Power Systems, 2nd ed., Springer, Chap. 2, pp. 18-40, 1996.

[28] R. Billinton, et al., "Probability distribution development in distribution system reliability evaluation," Elect. Power Compon. Syst., vol/issue: 30(9), pp. 907-916, 2002.

[29] J. Casazza and F. Delea, "Understanding Electric Power System: An Overview of the Technology and the Maketplace," The Institute of Electrical and Electronics Engineers (IEEE), 2003.

\section{BIOGRAPHIES OF AUTHORS}

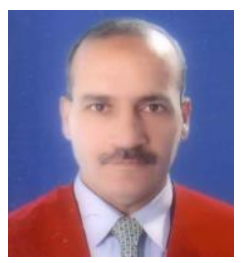

Ali S.K. Dalabeeh: received his B.S from Alleppo University/Engineering College/Syria in 1981 and PH.D in electrical engineering from Moscow power Institute in 1988. Currently he is an associate professor in electrical engineering department of Faculty of Engineering Technology/Al-Balqa' Applied University. His research interests include renewable energy and deregulation in electrical power systems.

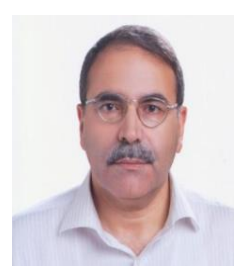

Abdallah R. Alzyoud: received his Master Degree in Electrical Power Engineering, Donetsk Polytechnic Institute, 1980. Ukraine And the Ph.D. in Electrical Power Engineering, Kiev Polytechnic Institute, 1992, Ukraine. He is currently promoted the Associate professor with Department of electrical engineering Faculty of Engineering Technology, Al- Balqa' Applied University, Al-Salt, Jordan. His research interests include solar energy, renewable energy and protection.

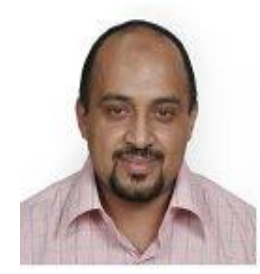

Anwar Al-Mofleh: received his B.Sc and MSc from Byelorussian Polytechnic academy in 1993. He is currently, working as lecturer in Al-Balqa Applied University in Jordan and as candidate for $\mathrm{PhD}$, at the fields of power and energy efficiency.

E-mail address: anwaralmofleh@yahoo.com, Tel (+962779430087)

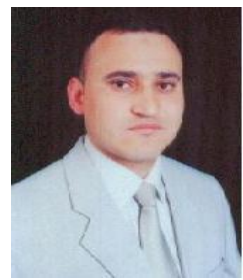

Ayman T. Hindi: received his B.S from Vinnitsa Technical University in 1995 and PH.D in electro engineering science from Vinnitsa Technical University in 2004. Currently he is an assistance professor in electrical engineering department in Najran University. His research interests include compensation of reactive power energy and consumption in electric installation and systems. 